\title{
Calciphylaxis in end-stage renal disease prior to dialytic treatment: a case report and literature review
}

This article was published in the following Dove Press journal: International Journal of Nephrology and Renovascular Disease 13 February 2015

Number of times this article has been viewed

\author{
Ramón Alberto Tamayo-Isla \\ Mauro Cuba de la Cruz \\ Internal Medicine Department, \\ Pietersburg Provincial Hospital, \\ Polokwane Kidney and Dialysis \\ Centre, Limpopo Province, South \\ Africa
}

Correspondence: Ramón Alberto Tamayo-Isla Internal Medicine Department, Pietersburg Provincial Hospital, Polokwane Kidney and Dialysis Centre, Corner Hospital and Dorp Street, Polokwane, Limpopo Province, South Africa, 0699

Email tamayoisla@gmail.com
Introduction: Calciphylaxis is a rare medical condition that is usually diagnosed in patients suffering from end-stage renal disease who are already receiving renal replacement therapy and in those post-transplantation. The pathogenesis still remains to be fully elucidated; hence, the treatment is not uniform. The prognosis is generally poor. The ulcerative stage exhibits a worse prognosis than the nonulcerative one. Calciphylaxis presenting in terminal kidney disease prior to dialytic treatment has only rarely been reported.

Case presentation: A 32-year-old female Caucasian clerk sought medical attention for increasing tiredness and lower limb skin ulcers. Polycystic kidney disease was diagnosed in her late father and two of her siblings. At the first nephrology consultation, obesity, pallor, bilateral flank masses with ballottement, and two ulcers with a dark necrotic center on the distal left leg were noted. In addition, another indurated light bluish lesion of $5 \mathrm{~cm}$ just above the right knee with intact skin was observed. All lesions were very tender and warm on touch. Laboratory results yielded hypercalcemia, hyperphosphatemia, anemia, and parathyroid hormone levels that were more than ten times the normal values in the patient, and with a glomerular filtration rate of $4 \mathrm{~mL} /$ minute. Skin biopsy confirmed the suspicion of calciphylaxis. The patient was placed on peritoneal dialysis with low $\mathrm{Ca}$ concentration baths, cinacalcet, and aluminum hydroxide. The results included correction of hypercalcemia, improvement of phosphate levels, and the product of both $\mathrm{Ca}$ and phosphate, but only a transitory decrease in serum parathyroid hormone levels. The ulcerations were completely healed after 2 months of treatment. Cinacalcet was discontinued after 18 months, but multiple large-size, nonulcerative indurated areas appeared 3 months later in the lower limbs after discontinuation of the drug. A parathyroidectomy performed 17 months later revealed a four-gland hyperplastic disease. The patient experienced relief of skin symptoms soon after the procedure and remains in a very satisfactory condition.

Conclusion: Calciphylaxis is a very complex clinical entity. Calciphylaxis presenting prior to dialytic treatment in end-stage renal disease is rare in the absence of a trigger. Cinacalcet and parathyroidectomy should be considered in selected patients.

Keywords: calciphylaxis, end-stage renal disease, parathyroid hyperplasia, cinacalcet

\section{Introduction}

Calciphylaxis is a rare complex medical syndrome that often has fatal clinical outcomes. Although most afflicted patients are described in end-stage renal disease (ESRD) or in post-transplantation, reports of nonrenal-related cases have been increasing. ${ }^{1-3}$ The pathogenesis is not yet well understood. The management remains supportive, aiming at correcting biochemical parameters; treatment remains tentative. Our case supports the view that calciphylaxis is not a complication of uremia in the absence of 
other aggravating factors or disorders, and that cinacalcet and parathyroidectomy are indicated in selected patients.

\section{Case presentation History}

A 32-year-old Caucasian female patient was referred to the renal clinic nearly 4 years ago for further evaluation of azotemia and autosomal dominant polycystic kidney disease. Her medical past revealed an 8-month history of nonhealing ulcers in the left leg and increasing fatigue. She was treated by her general practitioner with painkillers, oral antibiotics (cloxacillin), and local wound care. There was no history of smoking or alcohol. She was employed as a clerk. She is a mother of three healthy children. Autosomal dominant polycystic kidney disease was found in her father who died at the age of 50 years, and in two of her siblings.

\section{Physical examination}

At the first renal clinic visit, she was comfortable and well orientated in place, time, and person. However, she was severely pale, her blood pressure was normal, and her body mass index was $33 \mathrm{~kg} / \mathrm{m}^{2}$. There was no dyspnea, jaundice, or cyanosis. Neck vessels appeared normal and the hepatojugular reflux was normal too. Cardiovascular examination revealed a hyperkinetic nonsustained apex beat at the fifth intercostal space on the midclavicular line. No murmurs were heard. Abdominal palpation yielded palpable bilateral flank masses with ballottement. In the distal left half of her leg, a well-demarcated ulcer over the medial aspect was noted. The center of the lesion was very dark in color and dry. There was another extensive ulcerative area below and more distal to the previous lesion, toward the medial position, approaching the anterior dorsum of the foot (Figure 1). On touch, there was tenderness, increased local temperature, and induration. A light bluish macular lesion with ill-defined borders and a warm and tender indurated area about $5 \mathrm{~cm}$ wide with intact skin was found above the right knee as well.

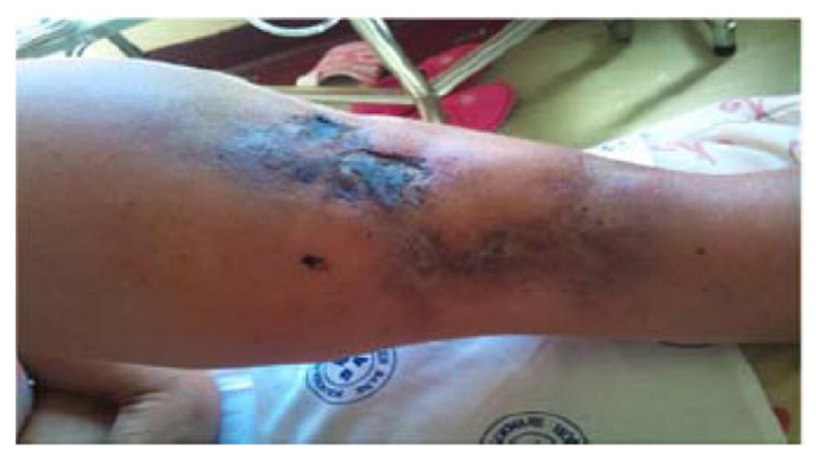

Figure I Skin manifestation of calciphylaxis. Left distal leg at the first predialysis visit.

\section{Ancillary examination}

The laboratory tests were reviewed prior to the initiation of continuous ambulatory peritoneal dialysis (CAPD) and at each follow-up visit (Table 1) at 4-6-week intervals. Severe anemia related to ESRD was managed successfully with erythropoietin (Recormon ${ }^{\circledR} ; 10,000 \mathrm{IU} /$ month) and intravenous iron (200 mg/month) support. Study of the coagulation profile revealed no concerns. Hypercalcemia, hyperphosphatemia, and severe hyperparathyroidism were documented in the predialysis evaluation. Echocardiogram showed diastolic dysfunction, normal valves, and no left ventricular hypertrophy, but there was an ejection fraction of $87 \%$ that did not fit with the study; it was therefore ignored in this report. Chest X-rays were normal. Neck computed tomography scan indicated tracheal calcifications. Lateral abdominal X-ray revealed linear calcification of the descending aorta (Figure 2). A technetium sestamibi parathyroid scan study done 2 months after initiating CAPD had suggested hypertrophy of the inferior right parathyroid gland and an adenoma in the left inferior parathyroid gland. Skin biopsy showed steatonecrosis with multiple mineral deposits suggestive of Ca in the subcutis; some blood vessels exhibited Ca deposits in the muscle layer and some vessels were partially thrombosed.

\section{Course and treatment}

Two weeks after the initial consultation, the patient was placed on CAPD. Hypercalcemia was treated with lowconcentration $\mathrm{Ca}$ dialysates (1.25\%). Cinacalcet (60 mg daily) was prescribed for 18 months and discontinued due to the prohibitive cost of the drug. Hyperphosphatemia partially subsided with dietary counseling and the use of aluminum hydroxide. The patient never took Ca pills or vitamin D analogs. The skin ulcers were managed with wound care by her general practitioner. The ulcers resolved 2 months after the initiation of dialytic treatment (Figure 3). Three months after the cessation of cinacalcet, multiple indurated, tender, and warm areas of various sizes ranging from $4-9 \mathrm{~cm}$ in width appeared on her thighs and below the knees (Figure 4). A bone scan of the whole body supported $\mathrm{Ca}$ deposits in the subcutaneous tissue (Figure 5). The patient sought medical assistance in the private sector since our center does not provide parathyroidectomy. Parathyroidectomy was performed after 17 months of cessation of cinacalcet. She experienced relief of her skin symptoms shortly after the parathyroidectomy, but complained of mental blunting and muscle cramps for 3 weeks. She continues to be followed up at our dialysis clinic, and is well overall. There has been a correction of hypocalcemia and of the associated symptoms. 
Table I Patient laboratory report; follow-up samples were taken at 4-8-week intervals

\begin{tabular}{llllll}
\hline & $\begin{array}{l}\text { Predialysis } \\
\text { visit }\end{array}$ & $\begin{array}{l}\text { Median } \\
\text { follow up }\end{array}$ & Range & $\begin{array}{l}\text { Postparathyroidectomy } \\
\text { (2-week sample) }\end{array}$ & $\begin{array}{l}\text { Reference } \\
\text { range }\end{array}$ \\
\hline Hemoglobin $(\mathrm{g} / \mathrm{dL})$ & 6.4 & 12.5 & $11.8-14.3$ & 10.4 & $12.1-16.3$ \\
Creatinine $(\mu \mathrm{mol} / \mathrm{L})$ & 996 & 943 & $842-1,014$ & 993 & $49-90$ \\
Corrected $\mathrm{Ca}(\mathrm{mmol} / \mathrm{L}) *$ & 2.74 & 2.44 & $2.07-2.51$ & 1.55 & $2.15-2.55$ \\
$\mathrm{Pi}(\mathrm{mmol} / \mathrm{L})$ & 3.66 & 2.55 & $1.9-2.69$ & 1.73 & $0.78-1.42$ \\
$\mathrm{Ca} \times \mathrm{Pi} \mathrm{product}(\mathrm{mmol} / \mathrm{L})$ & 9.29 & 6.12 & $3.87-6.59$ & 2.71 & $1.67-3.62$ \\
$\mathrm{PTH}(\mathrm{pmol} / \mathrm{L})$ & 201 & 183.4 & $21.8-301.4$ & 14.6 & $1.3-9.3$ \\
Albumin $(\mathrm{g} / \mathrm{L})$ & 37 & 36 & $31-37$ & 31 & $35-52$ \\
\hline
\end{tabular}

Notes: *Serum Ca corrected by albumin levels was calculated as follows: corrected calcium $(\mathrm{mmol} / \mathrm{L})=$ measured total Ca $(\mathrm{mmol} / \mathrm{L})+0.02(40-$ serum albumin $[\mathrm{g} / \mathrm{L}])$, where 40 represents the average albumin level in $\mathrm{g} / \mathrm{L}$.

Abbreviations: Pi, phosphates; PTH, parathyroid hormone.



Figure $\mathbf{2}$ Linear calcification of the descending aorta.

Note: Note the Tenckhoff catheter in the abdominal cavity; the X-ray was taken the day after catheter insertion.

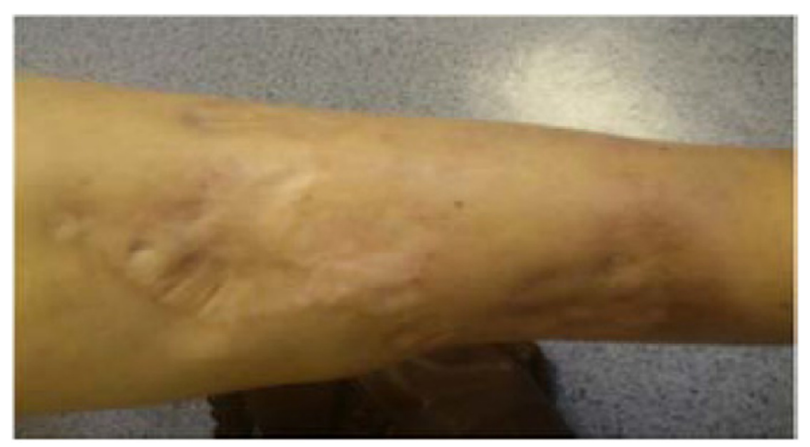

Figure 3 Skin manifestation of calciphylaxis. Left distal leg taken 4 months after the initiation of continuous ambulatory peritoneal dialysis.

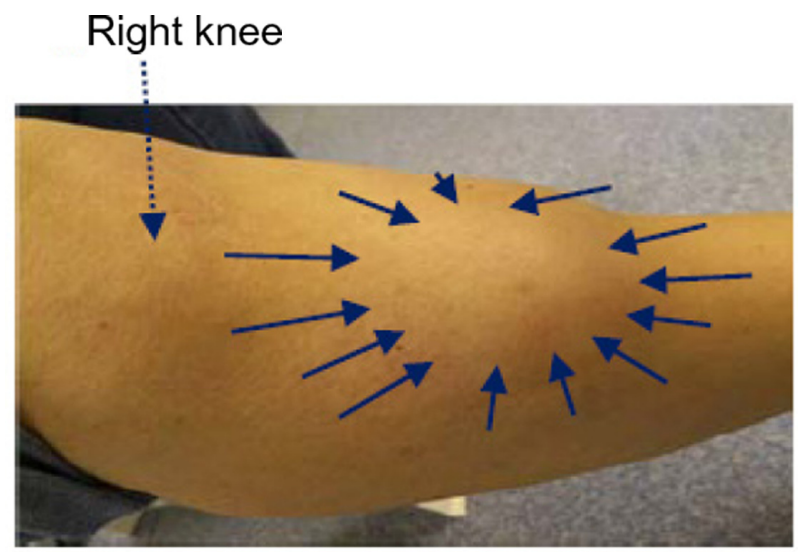

Figure 4 Skin manifestation of calciphylaxis. Right distal leg 3 months postcinacalcet treatment (note a large indurated area tender on touch with normal color, indicated by the continuous arrows).

\section{Discussion}

Initially, Seyle ${ }^{4}$ defined calciphylaxis as a condition of hypersensitivity to specific sensitizers and challengers in rats, and which included local and systemic reactions. ${ }^{5}$ In the human context, the application of this concept has been questioned due to the absence of a distinctive vasculopathy, as was observed in animal experiments. In view of a lack of understanding of the pathogenesis, the condition has received various names. ${ }^{5-8}$ Calcific uremic arteriolopathy, a widely used alternative that suggests uremia as a prerequisite, fits with our case; however, it is not present in all patients. Primary hyperparathyroidism, diabetes mellitus, malignancy, alcoholic liver, and connective tissue disease, amongst others, are often associated in nonuremic patients. Currently, the proposed definition of a syndrome of progressive vascular medial calcifications due to various diseases ${ }^{9}$ seems to reconcile some discrepancies in the literature.

Renal-related calciphylaxis has been an unsatisfying target for researchers. Renal patients have a tendency toward earlier vascular calcifications than the normal population. Key players in the pathogenesis of calciphylaxis are high 


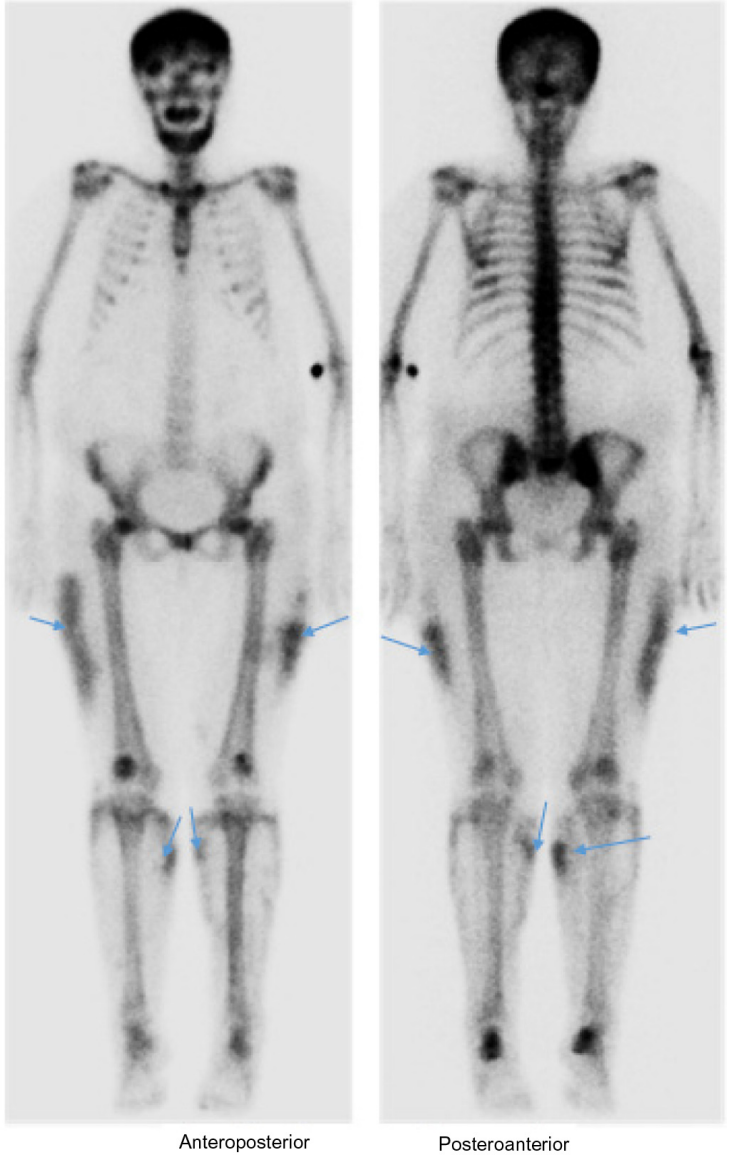

Figure 5 Whole-body bone scan.

Note: Subcutaneous Ca deposit observed (arrows) 3 months after the discontinuation of cinacalcet.

parathyroid hormone (PTH) levels, hyperphosphatemia, phosphate $(\mathrm{Pi})-\mathrm{Ca}$ products $(\mathrm{Ca} \times \mathrm{Pi})$, and uremia. Rogers et $\mathrm{al}^{10}$ have extensively reviewed the pathogenesis of calciphylaxis in uremic patients; the interaction of uremic toxins, hyperphosphatemia, and the dysregulation of human smooth cell physiology are initiating events. This "ongoing uremic milieu down-regulates inhibitors of vascular calcification: a2-Heremans Schmid glycoprotein/fetuin-A, matrix GLA protein (MGP)" ${ }^{10}$ Supposedly, the ensuing endothelial dysfunction, vasoconstriction, and intravascular thrombosis will promote ischemia and skin necrosis. However, the authors also pointed out that MGP is expressed in in vitro calcification models, and MGP-knockout mice display extensive vascular calcification, but not in calciphylaxis. ${ }^{10}$ Uncertainties in the understanding of the pathogenesis in uremia persist.

This condition can be diagnosed by taking into account the clinical manifestations, laboratory markers, and skin biopsy report. The clinical diagnosis might be suggested by evaluation of characteristic signs, such as the almost always bilateral ${ }^{7}$ violaceous skin lesions or subcutaneous large indurated nodular masses in high-risk patients. Fine and Zacharias ${ }^{7}$ observed that none of the patients who they thought had the disease had normal supportive investigations. In addition, they observed that biopsy was mostly unnecessary, and it posed a risk factor for new ulcerations and sepsis. ${ }^{7}$ The authors valued bone scan as a safe and a more reliable diagnostic tool than skin biopsy.

The overall prognosis of patients suffering from this syndrome is poor, depending largely on the underlying disease, comorbidities, location of the lesions, and phase of diagnosis. Lesions found in the upper extremities are associated with worse outcomes, probably due to the varying amount of fat tissue, as fat tissue exhibits a decrease in blood circulation, thus favoring the onset of the condition. A mortality rate of $63 \%$ associated to lesions found in the upper limb versus $32 \%$ for those lesions in the lower limbs was reported few years ago. ${ }^{11}$ Furthermore, in those patients who developed ulceration, a drastic increase in mortality above $80 \%$ at 6 months was observed. ${ }^{11}$ The most common cause of death is sepsis or the underlying medical problem. It has been suggested that a nonulcerating disease is an earlier phase and is far more common, ${ }^{7}$ which might go under-recognized or be confused with other pathologies.

We report a unique case of a patient who developed calciphylaxis prior to the initiation of dialytic treatment, and who did not receive any kind of medication for chronic kidney disease (CKD) or its associated disorders. Although this condition is commonly described in patients with terminal kidney disease, in predialysis it is rarely documented. Nayer et $\mathrm{al}{ }^{12}$ have recently published a case of a 72-year-old female with CKD who developed calciphylaxis prior to renal replacement therapy due to arteriosclerotic peripheral vascular disease. In accordance with Nayer et al's case study ${ }^{12}$ and reviews in preuremic patients, the following risk factors were present in this patient: Caucasian; female; obesity; age above 30 years; and disarrangement of mineral bone metabolism. From our review, we have found that this clinical entity is not a complication of uremia in the absence of other risk factors or challengers.

In our case, the second "hit" for the disease in the background of CKD has been attributed to primary hyperparathyroidism. The clue for this diagnosis was the presence of hypercalcemia during the predialysis evaluation. Hypercalcemia at the presentation of ESRD is an alarming sign requiring malignancy or, less likely, parathyroid gland disease to be excluded. At the onset of terminal kidney disease, patients experience severe disruption of the $\mathrm{PTH}-\mathrm{Ca}-\mathrm{Pi}$ axis; hyperphosphatemia, high PTH levels, and hypocalcemia are also often present. Hypocalcemia is explained 
Table 2 Main distinctive features in hyperparathyroidism

\begin{tabular}{llll}
\hline & Primary hyperparathyroidism & Secondary hyperparathyroidism & Tertiary hyperparathyroidism \\
\hline Blood $\mathrm{Ca}$ & High & Low & High \\
PTH & High & High & High \\
Urinary Ca & High & Low & Low \\
Main origin of the abnormality & Parathyroid gland & Kidneys & Kidney-parathyroid gland \\
Cause & Adenoma $(75 \%-80 \%)$ & Chronic kidney disease & Chronic dialysis \\
& Hyperplasia (10\%-15\%) & & \\
& Parathyroid carcinoma $(<4 \%)$ & & \\
\hline
\end{tabular}

Abbreviation: PTH, parathyroid hormone.

by the decreased synthesis of 1-alpha hydroxylase by the sick kidney, resulting in insufficient vitamin $\mathrm{D}$, which is necessary for $\mathrm{Ca}$ intestinal absorption and the disarray of mineral bone metabolism. But in contrast to serum $\mathrm{Ca}$, $\mathrm{Pi}$ is increased due to impaired renal excretion. The result is overstimulation of PTH production to maintain homeostasis. Table 2 summarizes the major abnormalities encountered in hyperparathyroidism.

To our surprise, the pathologist report did not support parathyroid adenoma as a cause of hyperparathyroidism, but of diffuse parathyroid hyperplasia (Figure 6), which is only cited in $10 \%-15 \%$ of patients with primary hyperparathyroidism. ${ }^{13}$ The distinction between primary and secondary disease by histology seems to be very difficult, although nuclear pleomorphism favors a primary origin, while gland nodularity favors a secondary cause. ${ }^{14} \mathrm{~A}$ case somewhat similar to ours featuring a parathyroid adenoma and secondary hyperparathyroidism in stage III CKD has been published recently by Brucculeri and Haydon, ${ }^{15}$ with beneficial results noted for cinacalcet after parathyroidectomy. In this case, the authors argued that the response of hypercalcemia after the subtotal gland removal was supportive of secondary hyperparathyroidism.

In our case, the use of cinacalcet and CAPD appeared to have halted the disease, despite the fact that PTH, Pi, and $\mathrm{Ca}$ were not sufficiently corrected. Although creatinine levels did not change significantly after the initiation of dialysis, a marked clinical improvement, healing of skin ulcers, and the patient's perception of well-being prompted the pursuit of CAPD. So far, she has survived 40 months, benefiting from all the advantages of peritoneal dialysis. In a retrospective study carried out by Weenig et al, ${ }^{16} 64$ patients were evaluated. An estimated survival rate of $45.8 \%$ was reported in the first year, but for those who received surgical debridement it was $61.6 \%$

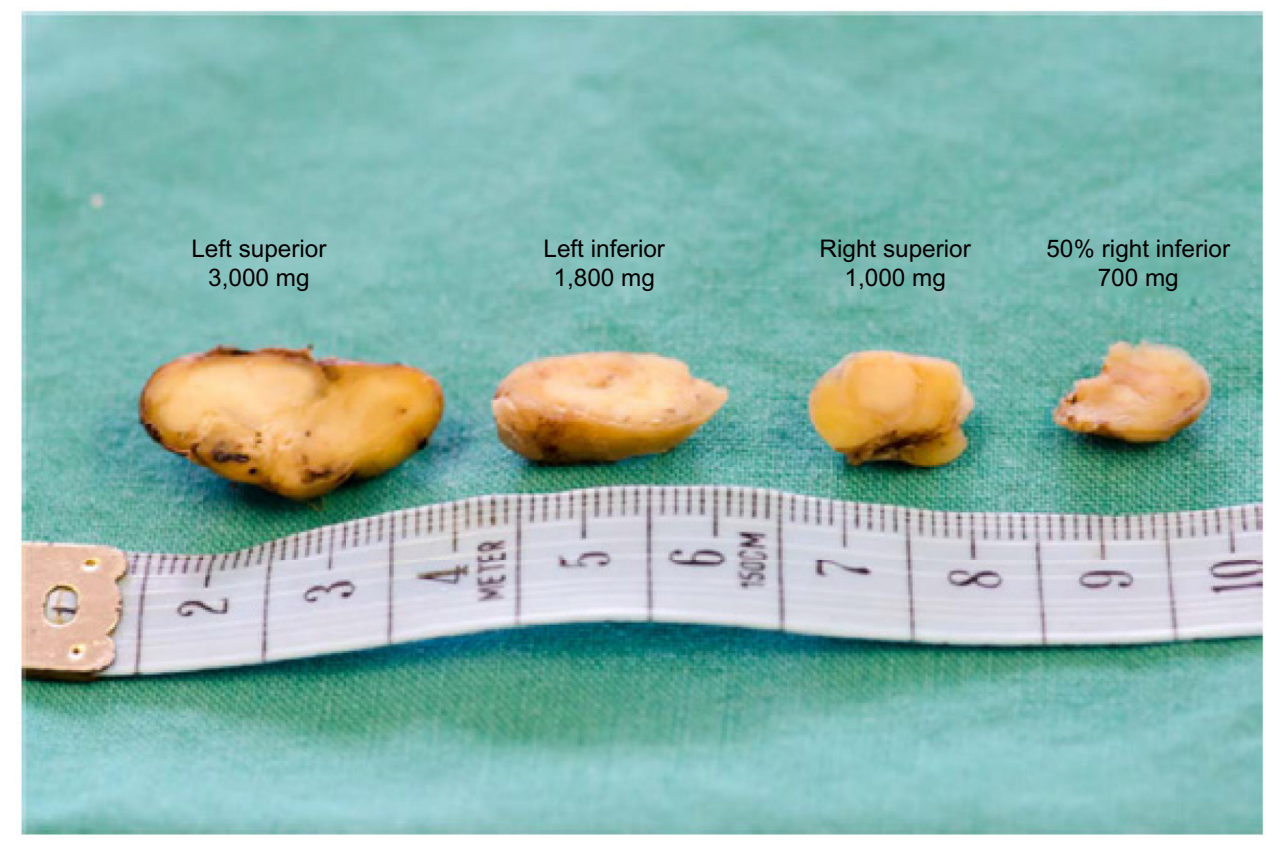

Figure 6 Patient's parathyroid glands. Note: Normal gland weighs $<50 \mathrm{mg}$. 
(17 patients), as compared to $27.4 \%$ for 46 patients who did not receive this treatment. ${ }^{16}$

No consensus in the management of the afflicted patients exists. Surgical and medical approaches are common practice. Early parathyroidectomy, diligent wound care, correction of biochemical abnormalities, and the use of sodium thiosulfate, phosphate-lowering therapy, steroids, and cinacalcet are commonly advocated strategies, ${ }^{9,17}$ but with ambiguous outcomes. Given the inconsistent survival outcomes reported postparathyroidectomy, ${ }^{7}$ the indication has become controversial, but in patients with suspected parathyroid gland disease, parathyroidectomy should remain an option.

This case highlights a few points of interest for clinical practice; the role of hypercalcemia in calciphylaxis and the use of cinacalcet and parthyroidectomy in selected patients are important medical interventions to be considered in the context of individualized medicine.

\section{Conclusion}

Calciphylaxis is a very complex clinical entity. Calciphylaxis presenting prior to dialytic treatment in ESRD is rare in the absent of a trigger. Cinacalcet and parathyroidectomy should be considered in selected patients.

\section{Acknowledgments}

We appreciate the kindness of Dr Kobus van Wyk for providing the photos of the patient's parathyroid glands. Professor Louis J van Bogaert has reviewed the re-edited version, for which we are thankful. Written informed consent was obtained from the patient for publication of this case report and the accompanying images.

\section{Author contributions}

RATI directed patient care, took photos, collected the patient's information prospectively and made substantial contributions to conception and design, acquisition of data, and analysis and interpretation of data. He also wrote the draft and the final version of the manuscript. MCC discussed the patient data, made substantial contributions to conception and design, acquisition of data, or analysis and interpretation of data; and critically revised the manuscript for important intellectual content. Both authors read and approved the final manuscript.

\section{Disclosure}

The authors report no conflicts of interest in this work.

\section{References}

1. Couto FM, Chen H, Blank RD, Drezner MK. Calciphylaxis in the absence of end-stage renal disease. Endocr Pract. 2006;12(4):406-410.

2. Nigwekar SU, Wolf M, Sterns RH, Hix JK. Calciphylaxis from nonuremic causes: a systematic review. Clin J Am Soc Nephrol. 2008;3(4): $1139-1143$.

3. Almafragi A, Vandorpe J, Dujardin K. Calciphylaxis in a cardiac patient without renal disease. Acta Cardiol. 2009;64(1):91-93.

4. Selye H. Calciphylaxis. Chicago, IL: University of Chicago Press; 1962.

5. Sowers KM, Hayden MR. Calcific uremic arteriolopathy: pathophysiology, reactive oxygen species and therapeutic approaches. Oxid Med Cell Longev. 2010;3(2):109-121.

6. Magro CM, Simman R, Jackson S. Calciphylaxis: a review. J Am Col Certif Wound Spec. 2010;2(4):66-72.

7. Fine A, Zacharias J. Calciphylaxis is usually non-ulcerating: risk factors, outcome and therapy. Kidney Int. 2002;61(6):2210-2217.

8. Fernández E. [Uremic calcifying ateriolopathy (calciphylaxis) with metabolic syndrome and diabetes mellitus. The current perspective]. Nefrologia. 2008;28(1):20-24. Spanish.

9. Wollina U. Update on cutaneous calciphylaxis. Indian J Dermatol. 2013;58(2):87-92.

10. Rogers NM, Teubner DJ, Coates PT. Calcific uremic arteriolopathy: advances in pathogenesis and treatment. Semin Dial. 2007;20(2): $150-157$.

11. Rodríguez-Villarreal I, Callejas R, Sánchez M, et al. Calcifilaxis o arteriopatía uremica calcificante: combinación de tratamientos [Calciphyalxis or calcific uremic arteriolopathy: combination of treatments]. NefroPlus. 2010;3(3):39-44. Spanish.

12. Nayer A, Virmani S, Gonzalez-Suarez M, et al. Pre-uremic calciphylaxis. Iran J Kidney Dis. 2014;8(3):252-256.

13. Carlson D. Parathyroid pathology: hyperparathyroidism and parathyroid tumors. Arch Pathol Lab Med. 2010;134(11):1639-1644.

14. Lawrence DA. A histological comparison of adenomatous and hyperplastic parathyroid glands. J Clin Pathol. 1978;31(7):626-632.

15. Brucculeri M, Haydon AH. Calciphylaxis presenting in early chronic kidney disease with mixed hyperparathyroidism. Int J Nephrol Renovasc Dis. 2011;4:157-160.

16. Weenig RH, Sewell LD, Davis MD, McCarthy JT, Pittelkow MR. Calciphylaxis: natural history, risk factor analysis, and outcome. $\mathrm{J} \mathrm{Am}$ Acad Dermatol. 2007;56(4):569-579.

17. Zitt E, König M, Vychytil A, et al. Use of sodium thiosulphate in a multi-interventional setting for the treatment of calciphylaxis in dialysis patients. Nephrol Dial Transplant. 2013;28(5):1232-1240.

\section{Publish your work in this journal}

The International Journal of Nephrology and Renovascular Disease is an international, peer-reviewed open-access journal focusing on the pathophysiology of the kidney and vascular supply. Epidemiology, screening, diagnosis, and treatment interventions are covered as well as basic science, biochemical and immunological studies. The journal welcomes original research, clinical studies, reviews \& evaluations, expert opinion and commentary, case reports and extended reports. The manuscript management system is completely online and includes a very quick and fair peerreview system, which is all easy to use. Visit http://www.dovepress.com/ testimonials.php to read real quotes from published authors. 